\title{
Isolated scaphocephaly
}

INSERM

\section{Source}

INSERM. (1999). Orphanet: an online rare disease and orphan drug data base. Isolated scaphocephaly. ORPHA:35093

Isolated scaphocephaly is a form of nonsyndromic craniosynostosis characterized by premature fusion of the sagittal suture. 